\title{
Corte Suprema de Justicia de la Nación Argentina
}

Causa: S., J. L. cl Comisión Nac. Asesora para la 1nt. de Personas Discapac. y otro s/ amparo

Buenos Aires, 5 de diciembre de 2017

VISTOS LOS AUTOS: "S., J. L. cl Comisión Nac. Asesora para la 1nt. de Personas Discapac. y otro s/ amparo

\section{CONSIDERANDO:}

Que la cuestión planteada por la recurrente guarda analogía con la debatida y resuelta en Fallos: 338: 488, a cuyos fundamentos y conclusiones cabe remitir y se dan por reproducidos en razón de brevedad.

Por ello, se declara procedente el recurso extraordinario y se confirma la sentencia apelada. Costas por su orden en razón de la naturaleza de la cuestión debatida (art. 68 del Código

Procesal Civil y Comercial de la Nación). Notifíquese y, oportunamente, remítase.

Ricardo Luis Lorenzetti - Elena I. Highton de Nolasco - Juan Carlos Maqueda - Carlos Fernando Rosenkrantz - Horacio Rosatti (en disidencia)

\section{EL DERECHO A LA SALUD DE PERSONAS CON DISCAPACIDAD Y SU COBERTURA POR PARTE DEL ESTADO}

\author{
HE RIGHT TO HEALTH OF PEOPLE WITH DISABILITIES AND THEIR COVERAGE BY THE \\ STATE
}

MARÍA FLORENCIA BLANCO PIGHI'

RESUMEN

El derecho a la salud es reconocido por la Constitución Argentina, pero, como todo derecho, no es absoluto. La Corte Suprema de Justicia de la Nación, mediante el fallo en análisis, establece ciertos requisitos para asegurar la cobertura por parte del Estado, de prestaciones que garanticen el acceso a este derecho para personas con discapacidad. El voto en disidencia establece que, muchas veces, apegarse a requisitos formales puede implicar cercenar el goce efectivo del derecho a la salud, que es de carácter constitucional.

\section{ABSTRACT}

The right to health is recognized by the Argentine Constitution, but, as every right, is not absolute. The Supreme Court of Justice, through the sentence to analyze, establishes certain requirements to ensure coverage by the State of benefits that guarantee access to this right for people with disabilities. The dissident vote establishes that, often, adhering to formal requirements may imply clogging the effective enjoyment of the right to health, which is constitutional in nature.

1 Abogada y Profesora en Ciencias Jurídicas, egresada de la Facultad de Derecho de la Universidad Nacional de Córdoba. Docente tutor de la Facultad de Derecho U.N.C. en el marco del programa: "Acompañamiento a las trayectorias estudiantiles" de la Secretaría de Asuntos Estudiantiles, U.N.C. Adscripta de la Cátedra "B" de Privado VII, Facultad de Derecho U.N.C. - Correo electrónico: florblancopighi@gmail.com 
Disidencia del Señor Ministro Doctor Don Horacio Rosatti CONSIDERANDO:

$1^{\circ}$ ) Que la madre del actor, en representación de su hijo declarado incapaz por padecer sindrome de down, inició una acción de amparo contra la Comisión Nacional Asesora para la Integración de las Personas Discapacitadas y el Servicio Nacional de Rehabilitación y Promoción de la Persona con Discapacidad, a fin de que se protegiera y reconociera el derecho a la cobertura total de las prestaciones que en atención a su discapacidad requiere, consistentes en el caso en una escolaridad especial de jornada simple en el Instituto El Taller, transporte desde el domicilio hasta el lugar de rehabilitación, sin limitaciones temporales, asi como la inmediata regularización de los montos adeudados a fin-de garantizar la continuidad de dicho tratamiento.

$2^{\circ}$ ) Que para fundar su pretensión, la demandante señaló que el actor habia asistido a dicha institución en la modalidad de Escolaridad Especial, jornada simple, desde 2001, como alumno becado, habia realizado un periodo de adaptación y había quedado incluido en el grupo de etapa IV del servicio de escolaridad primaria especial. Explicó que, al ser el actor afiliado al Instituto de Previsión y Seguridad Social de Tucumán -I.P.S.S.T.- que no otorga ningún tipo de cobertura de las prestaciones mencionadas, ni se encuentra adherida al Sistema de Obras Sociales a que hace referencia la ley 24.901, se acumuló una deuda con la institución edu-

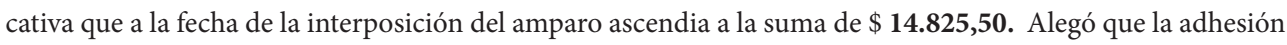
de la Provincia de Tucumán a la ley 24.901 -Sistema de Prestaciones Básicas para Personas con Discapacidadse perfeccionó mediante un convenio celebrado con la Nación a partir del año 2003 en el que la provincia optó expresamente por una incorporación gradual a dicho estatuto, que culminaría con el dictado de una ley que estableciera principios análogos a los enunciados en la citada norma, que todavía no ha sido sancionada. Además, puso de manifiesto que la propia provincia reconoció no tener instituciones para tratar la minusvalía del actor.

Palabras claves: Derecho a la salud - Derecho de Defensa - Debido Proceso - Obras Sociales - Personas con discapacidad

Key Words: Right to health - Defense Law - Due Process - Social Works - People with disabilities.

\section{Introducción}

En el presente texto se procederá a analizar el caso: "S., J. L. c/ Comisión Nac. Asesora para la Int. de Personas discapacitadas y otro s/ amparo" dictado por la Corte Suprema de Justicia de la Nación con fecha cinco de diciembre de 2017.

Mediante el mismo, el más alto Tribunal de nuestro país decidió que el Servicio Nacional de Rehabilitación y la Comisión Nacional Asesora para la Integración de las Personas Discapacitadas no se encontraban obligados a brindar la cobertura total de las prestaciones que la actora requería con motivo de su discapacidad, ni debían pagar las sumas que ésta adeudaba por la cobertura de dichos servicios.

Resulta por demás interesante, el voto en disidencia del Dr. Rosatti, quien se aparta del criterio sentado por la Corte Suprema, estableciendo la supremacía constitucional del derecho a la salud.

\section{El fallo}

La controversia que motiva la sentencia analizada, se suscita cuando la progenitora de un incapaz que padecía Síndrome de Down interpuso un amparo contra la Comisión Nacional Asesora para la Integración de las Personas Discapacitadas y el Servicio 
$3^{\circ}$ ) Que contra la sentencia de la Sala III de la Cámara Civil y Comercial Federal, que revocó el fallo de la instancia anterior que había admitido el amparo y condenado al Servicio Nacional de Rehabilitación y Promoción de la Persona con Discapacidad a hacerse cargo de las prestaciones reclamadas por el actor, este dedujo el recurso extraordinario, que fue concedido.

$4^{\circ}$ ) Que para decidir de ese modo, el a quo juzgó - por remisión al precedente de Fallos: 338:488- que la obligación del Estado Nacional era subsidiaria y que la actora no había cumplido los requisitos exigidos por la normativa vigente para obtener la cobertura solicitada por no haber demostrado su falta de afiliación a una obra social y la imposibilidad de afrontar por sí sola las prestaciones requeridas.

$5^{\circ}$ ) Que el remedio intentado suscita cuestión federal bastante para su consideración por la vía intentada, en la medida en que la sentencia apelada ha sido contraria a las normas superiores en que se funda el apelante.

En efecto, tanto los agravios de la recurrente como las consideraciones dadas por el Defensor Oficial ante la Corte, ponen de manifiesto que lo que aqui se discute atañe a la aplicación, inteligencia e interpretación de normas federales como las que tutelan el derecho a la salud de los discapacitados y las que regulan el Sistema de Prestaciones Básicas para Personas con Discapacidad (ley 24.901). Eh este plano, el Tribunal no se encuentra limitado por los argumentos de las partes o del a qua, sino que le incumbe realizar una declaración sobre el punto debatido (Fallos: 320:1602 y 323:1656).

$\left.6^{\circ}\right)$ Que no se encuentra discutido que el hijo de la demandante ha sido declarado incapacitado por las autoridades administrativas pertinentes (fs. 172); que es afiliado al Instituto de Previsión y Seguridad Social de Tucumán, institución que, según surge de lo expresado a fs. 207, no se encuentra comprendida entre los sujetos obligados por la ley 24.901 (acta número 184 de la Reunión del Directorio del Sistema de Prestaciones Básicas del 17 de mayo de 2005). Tampoco ha sido refutado por la demandada que el actor ha recibido su rehabilitación en el Instituto El Taller en carácter de "becado" y

Nacional de Rehabilitación y Promoción de la Persona con Discapacidad, a los fines de que se protegiera y reconociera el derecho a la cobertura total de las prestaciones que en atención a su discapacidad, requiere su hijo. Las que consistían en: una escolaridad especial de jornada simple en un instituto particular, transporte desde el domicilio del incapaz hasta el lugar de rehabilitación, sin limitaciones temporales, así como la inmediata regularización de los montos adeudados, para garantizar la continuidad de dicho tratamiento.

Es necesario destacar que el niño había concurrido al establecimiento educativo desde hacía varios años, con el carácter de becado, pero que, al cesar la beca y al verse sus padres imposibilitados de hacer frente a los costos del mismo, es que se interpuso el amparo que motiva el fallo en tratamiento. Que, la afiliación con la que contaba el actor, no otorga cobertura de ninguna de las prestaciones necesarias ni se encuentra adherida al Sistema de Obras Sociales que hace referencia la Ley 24.091.

En primera instancia, se hace lugar al reclamo de la actora, condenado al Servicio Nacional de Rehabilitación y Promoción de la Persona con Discapacidad a hacerse cargo de las prestaciones reclamadas. Al ser apelada la sentencia, la Sala III de la Cámara Civil y Comercial Federal de Tucumán revoca el fallo del a quo, lo cual motiva la interposición del Recurso Extraordinario que genera la intervención del más alto Tribunal de nuestro país en la resolución de la controversia.

Así las cosas, la Corte Suprema de Justicia de la Nación, mantiene lo sentenciado por el tribunal de segunda instancia, rechazando el amparo interpuesto por la parte actora. Esta decisión se motiva en un criterio ya establecido por el más alto tribunal argentino, en cuanto a que, la obligación del Estado Nacional es subsidiaria y que la parte actora no había cumplido los requisitos exigidos por la normativa vigente (Ley 24.091) para obtener la cobertura solicitada. 
que cuando dicha circunstancia cesó, sus progenitores no pudieron pagar la cuota mensual, generándose una deuda que -en el lapso de desafíos- ascendió a la suma de \$14.825,50.

En autos no solo ha sido admitida la necesidad de las prestaciones que se requieren, sino que del informe evolutivo integral emitido por El Taller también surge que el rendimiento pedagógico del actor durante los años de escolaridad ha sido satisfactorio y su interrupción tentaría contra el progreso logrado (fs. 188/189).

$7^{\circ}$ ) Que este Tribunal ha considerado que el derecho a la vida es el primer derecho de la persona humana reconocido y garantizado por la Constitución Nacional (Fallos: 302:1284; 310:112). También ha sostenido que el hombre es el eje y centro de todo el sistema jurídico y que, en tanto fin en sí mismo, la inviolabilidad de la persona constituye un valor fundamental con respecto al cual los restantes valores tienen siempre carácter instrumental (Fallos: 316:479, votos concurrentes).

A partir de lo dispuesto en los tratados internacionales con jerarquía constitucional (art. 75, inc. 22, de la Ley Suprema), ha reafirmado en diversos pronunciamientos el derecho a la preservación de la salud y ha destacado la obligación impostergable que tiene la autoridad pública de garantizar ese derecho con acciones positivas, sin perjuicio de las obligaciones que deban asumir en su cumplimiento las jurisdicciones locales, las obras sociales o las entidades de la llamada medicina prepaga (Fallos: 323:3229 in re "Campodónico de Beviacqua"; 321:1684; 323:1339, mayoría y votos concurrentes y dictamen del señor Procurador General de la Nación a cuyos fundamentos se remiten).

La obligación de instrumentar acciones positivas en tutela de las personas con discapacidad fue consagrada por el constituyente argentino en el año 1994 en el arto 75, inc. 23, donde se dispone que corresponde al Congreso Nacional "legislar y promover medidas de acción positiva que garanticen la igualdad real de oportunidades y de trato, y el pleno goce y ejercicio de los derechos reconocidos por esta Constitución y por los tratados internacionales vigentes sobre derechos humanos, en particular respecto de los niños, las mujeres, los ancianos y las personas con discapacidad".

Es decir que, según lo normado en los arts. $3^{\circ}$ y $4^{\circ}$ de la Ley 24.091, el Estado Nacional solo se encuentra obligado a cubrir las prestaciones previstas por la normativa, cuando la persona con discapacidad carece de cobertura de obra social y no cuenta con los medios adecuados para hacer frente a las erogaciones que demandan dichas prestaciones. Según la Corte Suprema de Justicia de la Nación, éstos son requisitos insoslayables a los fines de cualquier reclamo de cobertura. Los cuales, según el criterio del mencionado tribunal, no se encuentran debidamente cumplimentados en el caso de marras, motivo por el cual, tanto la Cámara de Apelaciones como la Corte Suprema de Justicia de la Nación, rechazan el amparo interpuesto.

Otro de los fundamentos de la Corte Suprema de Justicia de la Nación, para sostener el criterio establecido en el fallo en cuestión, es que el principio de división y equilibrio de los poderes impide al Poder Judicial a legislar, y que, en este sentido, todo juez, al fallar, debe atenerse al texto de la ley. En el caso de la Ley 24.091, resulta claro que son requisitos ineludibles los mencionados ut supra, y que, ante su ausencia, no se puede responsabilizar al Estado Nacional por la cobertura de las prestaciones que la persona con discapacidad necesita.

Se mantiene así la doctrina del más alto tribunal argentino, que ha establecido que "/as leyes deben interpretarse conforme el sentido propio de las palabras, computando que los términos utilizados no son superfluos sino que han sido empleados con algún propó sito, sea de ampliar, limitar o corregir los preceptos". ${ }^{2}$ Queda vedado, desde esta óptica, forzar interpretaciones que impliquen que, los jueces, realicen labores legislativas que tienen prohibidas constitucionalmente.

2 CSJN 289/2014 (50-P) ICS1. RECURSO DE HECHO. P., A. el Comisión Nacional Asesora para la Integración de las Personas Discapacitadas y otro s/ amparo. Disponible en: www.csjn.gov.ar 
En el mismo sentido, la Convención sobre los Derechos de las Personas con Discapacidad, instrumento con jerarquía constitucional en el marco del arto 75, inc. 22 mencionado, sostiene que "Los Estados Partes reconocen que las personas con discapacidad tienen derecho a gozar del más alto nivel posible de salud sin discriminación por motivos de discapacidad" (art. 25) Y que "los Estados Partes reconocen el derecho de las personas con discapacidad a la educación. Con miras a hacer efectivo este derecho sin discriminación y sobre la base de la igualdad de oportunidades, los Estados Partes asegurarán un sistema de educación inclusivo a todos los niveles así como la enseñanza a lo largo de la vida ..." (art. 24, 1).

El art. 24.2, inc. a de la convención en cita establece que "los Estados Partes tomarán todas las medidas necesarias para asegurar que todos los niños y las niñas con discapacidad gocen plenamente de todos los derechos humanos y libertades fundamentales en igualdad de condiciones con los demás niños y niñas" (art. inc. 1) y asegurarán que "las personas con discapacidad no queden excluidas del. sistema general de educación por motivos de discapacidad, y que los niños y las niñas con discapacidad no queden excluidos de la enseñanza primaria gratuita y obligatoria ni de la enseñanza secundaria por motivos de discapacidad".

$8^{\circ}$ ) Que, con específica referencia a la pretensión debatida en el subjudice, la Ley Nacional 22.431 instituyó un sistema de protección integral de las personas con necesidades especiales tendiente a abarcar todos los aspectos relativos a su inserción dentro de la sociedad. Por su parte, la ley 24.901 creó un sistema de prestaciones básicas de atención integral a favor de las personas con discapacidad para brindarles asistencia integral, poniendo su cobertura a cargo de obras sociales. Finalmente, la Provincia de Tucumán ratificó el convenio de adhesión a la citada ley nacional, optando por una incorporación gradual al sistema único de prestaciones básicas para personas con discapacidad. Es decir, si bien la tutela de los derechos estaría jurídicamente reconocida, su concreción fue estipulada con carácter gradual y bajo el compromiso de dictar en el ámbito provincial un régimen normativo que estableciera principios análogos a los de la ley 24.901, algo que aún no ha acontecido. Dicha omisión no puede conllevar la vulneración del derecho constitucional señalado, por lo que cabe con-

Sumado a ello, la Provincia de Tucumán ratificó el convenio de adhesión a la Ley 24.091, optando por una incorporación gradual al sistema único de prestaciones básicas para personas con discapacidad. Es decir, si bien la tutela de los derechos estaría jurídicamente reconocida, su concreción fue estipulada con carácter gradual y bajo el compromiso de dictar en el ámbito provincial un régimen normativo que estableciera principios análogos a los de la normativa citada, algo que aún no ha acontecido.

\section{EI voto en disidencia}

La sentencia en cuestión, remite a fundamentos ya vertidos con anterioridad por la Corte Suprema de Justicia de la Nación, razón por la cual lo más interesante que plantea la misma es, el voto en disidencia del Dr. Rosatti.

Su planteo es claro, ¿qué debe primar: el derecho a la salud o el cumplimiento de los requisitos de la Ley 24.091? De un análisis constitucional de las normas, el cual realiza de manera exhaustiva en su voto, parece surgir que, al ser el derecho a la salud un derecho constitucionalmente reconocido por nuestra Carta Magna, como así también por tratados internacionales con jerarquía constitucional en virtud del art. 75 inc. 22, debe primar ese derecho, por encima de cualquier interpretación que se realice de una ley infra constitucional, como lo es la Ley 24.091.

Sumado a este razonamiento, se plantea que la existencia de los requisitos exigidos por la normativa en cuestión ha quedado demostrada en autos, y que, no han sido controvertidos por la parte contraria. Es decir, que, realizando una interpretación amplia de todo lo actuado, se ha acreditado el cumplimiento de la ley vigente.

También se puntualiza en que, ha quedado admitida la necesidad de las prestaciones 
cluir en la presente causa y a la luz de las específicas circunstancias normativas que le atañen, que el Estado Nacional debe responder al caso, sin perjuicio de los derechos que le correspondan a posteriori, para repetir del Estado provincial lo que considere legítimo.

Este razonamiento no implica afectar el principio de federalismo ni pone en crisis las facultades reservadas por los gobiernos locales en la organización de su sistema de salud, que debe ser concebido -en el caso específico en que se analiza- en base a un federalismo de concertación, en el que la omisión del Estado provincial de adoptar las medidas legislativas necesarias no puede sostenerse como óbice para la efectiva vigencia de derechos constitucionales fundamentales, dejando establecida la responsabilidad que cabe también en esta materia a las jurisdicciones provinciales. Tal como ha dicho esta Corte, "lo expresado pone en evidencia la función rectora que ejerce el Estado Nacional en este campo y la labor que compete al Ministerio de Salud y Acción Social, como autoridad de aplicación, para garantizar la regularidad de los tratamientos sanitarios coordinando sus acciones con las obras sociales y los estados provinciales, sin mengua de la organización federal y descentralizada que corresponda para llevar a cabo tales servicios" (Fallos: 323: 3229, considerando 27).

Complementariamente, no puede obviarse en esta instancia que el Estado Nacional ha asumido compromisos internacionales encaminados a promover y facilitar la vigencia de los derechos, sin que el federalismo constituya obstáculo para ello (Pacto Internacional de Derechos Económicos, Sociales y Culturales, art.28; Convención Americana sobre Derechos' Humanos, art. 28.2, no siendo razonable desligarse de los deberes asumidos so pretexto de la inactividad de otras entidades públicas o privadas, máxime cuando ellas participan de un mismo sistema sanitario y lo que se halla en juego es la rehabilitación integral del minusválido, que debe ser tutelada por todos los departamentos gubernamentales (Fallos: 323:3229, ya citado, considerando 21).

9) Que, por lo demás, no cabe imponer a la persona con discapacidad una mayor mortificación que la que su propio estado le ocasiona, compeliéndola a acudir a tratamientos ajenos a su cobertura de salud, máxime cuando el traslado del afectado fuera de la órbita de su asistencia médica habitual representa un dispendio de

que se requieren y, a su vez, del informe evolutivo integral, emanado de la institución a la que concurría el incapaz, surge que el rendimiento pedagógico del actor, durante los años de escolaridad, ha sido satisfactorio y que, su interrupción atentaría contra el progreso logrado.

Por otro lado, plantea, que la omisión de la Provincia de Tucumán en cuanto a legislar los alcances de su adhesión a la normativa nacional, no puede conllevar la vulneración de un derecho constitucional, por lo que, el Estado Nacional debe responder en este caso, sin perjuicio de los derechos que le correspondan a posteriori, para repetir del Estado provincial lo que considere legítimo y sin que ello presuponga afectar de manera alguna la forma de gobierno Federal.

Se debe tener en cuenta que, según Juan A. Seda:

"la legitimación pasiva es amplia, ya que hay normas de carácter nacional y provincial que expresan garantías y prestaciones para las personas con discapacidad. Siguiendo este razonamiento, el reconocimiento de derechos en leyes nacionales, pondría al Estado nacional en situación de garante de esos derechos"3.

Por estos motivos el Dr. Rosatti se aparta del planteo realizado por el resto de los integrantes de la Corte y establece que el Estado Nacional debe responder.

En idéntico sentido, se ha expedido otro tribunal al establecer que: "En síntesis, las disposiciones constitucionales que garantizan el derecho invocado por la accionante, plasmadas en la ley 24.901 con alcance amplio, no permiten una interpretación de esa norma,

3 SEDA, Juan Antonio (2017): DISCAPACIDAD Y DERECHOS: IMPACTO DE LA CONVENCIÓN SOBRE LOS DERECHOS DE LAS PERSONAS CON DISCAPACIDAD. Ciudad Autónoma de Buenos Aires: Editorial Jusbaires. Pág. 118. 
fondos y recursos humanos, que sustrae posibilidades de tratamiento a otros enfermos que lo necesitan dentro del sistema general de salud pública.

Por ello, el Tribunal resuelve: Declarar procedente el recurso extraordinario, revocar la sentencia apelada por los fundamentos de la presente y confirmar la de primera instancia. Notifíquese y devuélvase.

Horacio Rosatti

o de las que la reglamentan, que conduzca a una restricción irrazonable de la protección acordada por la Constitución Nacional y los Tratados Internacionales..."4

\section{Los derechos de las personas con discapacidad y su raigambre constitucional}

Resulta claro que los derechos constitucionalmente reconocidos no son absolutos, que deben ser regulados por las leyes que reglamentan su ejercicio, pero debemos ser cautos en cuanto a que algunas reglamentaciones, o la falta de las mismas, puedan provocar lisa y llanamente la imposibilidad de ejercer ese derecho.

El derecho a la salud, a la educación y a la inclusión que tienen las personas con discapacidad es indiscutido, tanto desde nuestra normativa interna como desde la órbita de la legislación internacional, la que, en muchos casos, tiene raigambre constitucional desde 1994.

Asimismo, ha dicho la doctrina que:

"del juego armónico de los derechos reconocidos en la Convención Internacional sobre los Derechos de las Personas con Discapacidad (...) y nuestra Carta Magna, la persona con discapacidad es sujeto de preferente tutela."

Si es un sujeto de tutela preferente, como lo es también, por ejemplo, el consumidor, en caso de dudas ante la interpretación de una ley, podríamos decir que debemos inclinarnos por aquella que sea más favorable a la persona con discapacidad.

Limitar estos derechos conforme a requisitos formales de una norma infra constitucional, resulta, al menos, cuestionable. A pesar de ello, este ha sido el criterio que ha seguido nuestro más alto Tribunal.

Es llamativo como, el Poder Judicial, en muchas ocasiones, y sobre todo en temáticas relacionadas a la cobertura de salud, es reacio a imponer sobre el Estado obligaciones que, en definitiva, nuestras propias normas, ponen sobre Él. Más aún si se tiene en cuenta que el derecho a la salud es un derecho social, especialmente protegido por el ordenamiento jurídico materializada en el ensanchamiento del acceso jurisdiccional y de la garantía de la tutela judicial efectiva.

Que, asimismo, el Poder Legislativo, también en ocasiones, incumple el mandato constitucional del art. 75 inc. 23, el que, dentro de las obligaciones del Congreso de la Nación, impone: "Legislar y promover medidas de acción positiva que garanticen la igualdad real de oportunidades y de trato, y el pleno goce y ejercicio de los derechos reconocidos por esta Constitución y por los tratados internacionales vigentes sobre derechos

4 CC Fed, sala I, "V.A.B. c/ Swiss Medical S.A." 21/5/2014.

5 Hector, María E. y Saires, Gustavo A. Doctrina del día: El discapacitado. Sujeto de preferente tutela constitucional. Publicado en Doctrina Judicial 15/02/2012. http://thomsonreuterslatam.com/2012/05/doctrina-del-dia-el-discapacitado-sujeto-de-preferente-tutela-constitucional/ (Fecha de consulta: 10 de julio de 2018) 
humanos, en particular respecto de los niños, las mujeres, los ancianos y las personas con discapacidad".

Incluso, la Corte Suprema ha dicho en otra oportunidad que, "a partir de lo dispuesto en los tratados internacionales que tienen jerarquía constitucional (art. 75 inc. 22, Ley Suprema), ha reafirmado en recientes pronunciamientos el derecho a la preservación de la salud- comprendido dentro del derecho a la vida- y ha destacado la obligación impostergable que tiene la autoridad pública de garantizar ese derecho con acciones positivas, sin perjuicio de las obligaciones que deban asumir en su cumplimiento las jurisdicciones locales, las obras sociales o las entidades de la llamada medicina prepaga". ${ }^{6}$

Es importante tener en cuenta, que en el caso en cuestión, no solo se trata de garantizar el derecho a la salud de la persona con discapacidad, sino también su acceso a la educación. En este sentido se ha dicho: "El ámbito educativo es uno de los principales escenarios donde se disputa el reconocimiento por la igualdad de derechos de las personas con discapacidad"7

Cabe entonces interpelarnos: ¿Puede la omisión del poder legislativo de la Provincia de Tucumán ser causa suficiente para no brindar la cobertura requerida? ¿Puede aplicarse de manera tan estricta el cumplimiento de los requisitos exigidos por la Ley 24.091 que implique impedir el goce efectivo del derecho a la salud y a la educación por parte del actor?

\section{A modo de conclusión}

La doctrina sentada por la Corte Suprema de Justicia de la Nación en la actualidad es clara, solo el cumplimiento efectivo de lo normado por los artículos tres y cuatro de la Ley 24.091 generan la responsabilidad del Estado de cubrir las prestaciones necesarias para asegurar el derecho a la salud de personas con discapacidad. La falta de acreditación de los mismos, hace que dicha responsabilidad recaiga sobre el propio discapacitado, o su familia, sin que ello genere una vulneración del derecho a la salud.

Así, uno de los argumentos que señala el más alto tribunal es que, los jueces no pueden extralimitarse en sus rol constitucional de intérpretes de la ley, a los fines de forzarla a decir lo que ésta no dice.

Por otro lado, resulta enriquecedor el voto en disidencia del Dr. Rosatti, ya que empieza a abrir el camino a cuestionar este razonamiento de la Corte Suprema de Justicia de la Nación, que no tiene por qué ser considerado correcto únicamente por haber sido mantenido a lo largo del tiempo. Incluso, podría pensarse que, los argumentos esgrimidos en el voto disidente, pueden llegar a ser el puntapié inicial para un cambio de criterio de nuestro más alto Tribunal. A su criterio, la supremacía constitucional del derecho a la salud de las personas discapacitadas debe imponerse, sobre cualquier interpretación de la normativa vigente que pueda ser realizada.

Así, una conjugación del derecho a la igualdad, a la educación, a la inclusión y a la salud, impone, desde la óptica del voto disidente, la obligación del Estado Nacional de garantizar, a la persona discapacitada, el acceso a las prestaciones que le permitirán su desarrollo pleno. Todo ello, a la luz de la normativa constitucional, internacional y nacional, vigente y obligatoria para nuestro país.

6 "C. de B., A.C. c/ Secretaría de programas de salud y otro". CSJN, 24/10/2000. Disponible en: www.csjn.gov.ar

7 SEDA, Juan Antonio (2017), Op. Cit. Pág 106. 